\title{
Solid road environment and its hazards
}

\author{
Marcin Budzyński ${ }^{1, *}$, Tomasz Radzikowski ${ }^{2}$, and Robert Zalewski ${ }^{3}$ \\ ${ }^{1}$ Gdansk University of Technology, Faculty of Civil and Environmental Engineering, Gdansk, Poland \\ ${ }^{2}$ Regional Road Authority in Olsztyn, Olsztyn, Poland \\ ${ }^{3}$ Regional Police in Olsztyn, Olsztyn, Poland
}

\begin{abstract}
Accidents that involve vehicles departing the road tend to have very high severity, as they often result in the vehicle hitting a permanent obstacle (which can be a tree, a pole, facility pillar, front wall of a culvert or a barrier). In recent years, this type of accident caused approx. $19 \%$ of all road deaths in Poland. A particularly high risk can be observed on roads located in northern and western voivodships, with many avenues of trees along the roadside. The paper will present the major road user hazards and their locations, based on the example of detailed analyses conducted for the area of the Warminsko-Mazurskie voivodship in Poland. In the paper, the authors will also present measures that can be applied to improve the safety of road users by improving roads managed by local governments in Warminsko-Mazurskie.
\end{abstract}

\section{Introduction}

Run-off-road accidents tend to be very severe because when a vehicle leaves the road, it will often crash into a solid obstacle (tree, pole, supports, front wall of a culvert, barrier). A statistical analysis of the data shows that Poland's main roadside hazard is trees and the severity of vehicles striking a tree in a run-off-road crash. The risks are particularly high in north-west Poland with many of the roads lined up with trees. Because of the existing rural road cross-sections, i.e. having trees directly on road edge followed immediately by drainage ditches, vulnerable road users are prevented from using shoulders and made to use the roadway. With no legal definition of the road safety zone in Polish regulations, attempts to remove roadside trees lead to major conflicts with environmental stakeholders. This is why a compromise should be sought between the safety of road users and protection of the natural environment and the aesthetics of the road experience. Rather than just cut the trees, other road safety measures should be used where possible to treat the hazardous spots by securing trees and obstacles and through speed management. Accidents that are directly related to the road environment fall into the following categories (based on police SEWIK database): hitting a tree, hitting a barrier, hitting a utility pole or sign, vehicle rollover on the shoulder, vehicle rollover on slopes or in ditch.

The main consequence of a roadside hazard is not the likelihood of an accident itself but of its severity [1]. Poland's roadside accident severity is primarily the result of poor design or operation of road infrastructure. This comes as a consequence of a lack of regulations or poorly defined regulations and failure to comply with road safety standards.

* Corresponding author: mbudz@.pg.gda.pl 
As we know from a number of studies looking at how specific road factors affect safety, the roadside environment and its components (vegetation, shoulders, embankments, drainage ditches, poles, signs, engineering objects, etc.) are very critical [1-5].

Safety barriers are also part of the roadside. While they protect motorists from hitting an obstacle or stop vehicles from leaving the road in the case of steep embankments, they are obstacles themselves, which if poorly designed and built, may pose a serious risk.

\section{Analysis of statistical data}

Between 2013 and 2015 there were 16,500 accidents related to the roadside (11\% of all accidents in that period). The accidents involved 20,700 people injured (16\%), including 6,400 seriously injured (16\%) and 2,100 people killed (24\%). Figure 1 shows the types of roadside-related accidents across the country. As much as $61 \%$ of fatalities are caused by hitting a tree. The severity of accidents was analysed for the different types of run-off-road accidents (the number of fatalities per 100 accidents). The following are the results: hitting a barrier -10 , hitting a tree -23 , hitting a sign or utility pole -9 , rollover -7 . As the figures show, run-off-road accidents are clearly most severe when they involve hitting a tree.

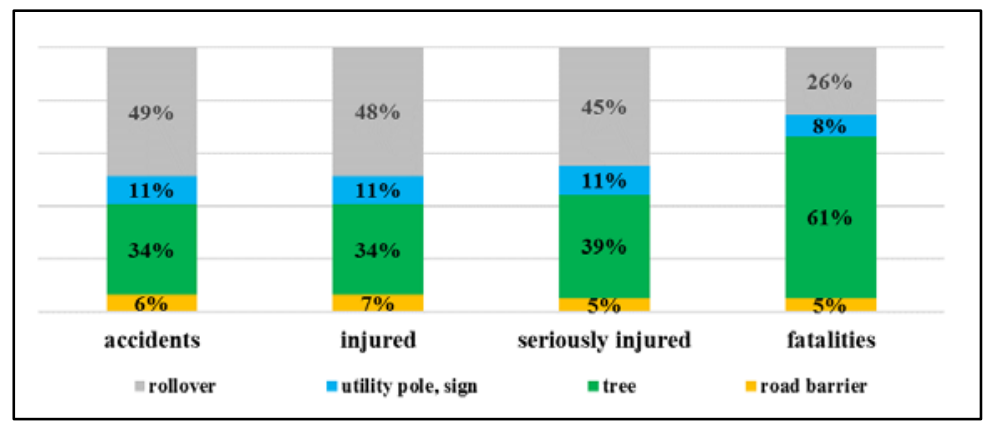

Fig. 1. Types of accidents involving the roadside in Poland.

The region of Warmińsko-Mazurskie was analysed for roadside accidents by road category. Run-off-road accidents are most common on regional roads - $15 \%$, national roads - $9 \%$ and others $-10 \%$. As regards fatalities, the majority occurred on other roads at $24 \%$, on regional roads $22 \%$ and on national roads $11 \%$. Safety of national roads is much better than in the other road classes. This is because they feature fairly good technical standards and have a high share of upgraded roads (no roadside trees). Figure 2 shows the share of fatalities in roadside-related crashes in the region of Warmińsko-Mazurskie. As much as $62 \%$ of casualties occur on county roads and $44 \%$ on regional roads.

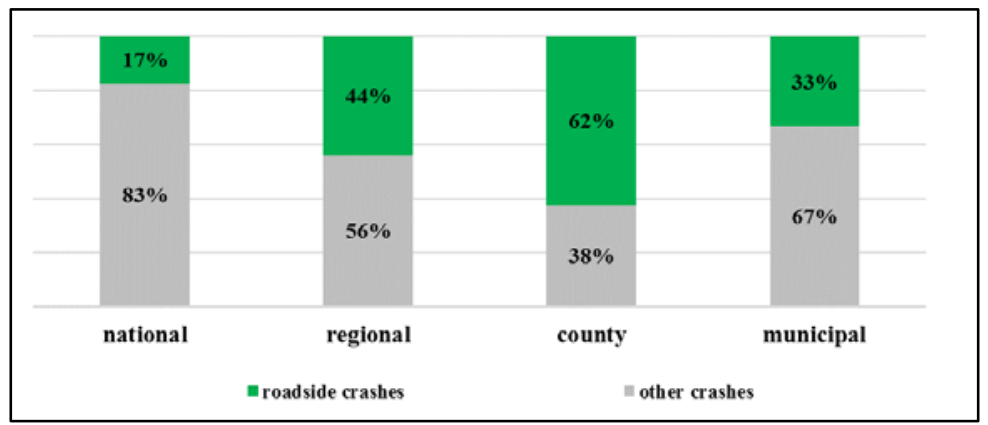

Fig. 2. Share of fatalities in roadside accidents by road category in the region of WarmińskoMazurskie. 
Roadside accidents were also analysed for regional distribution. It was found that in the years 2013 - 2015 the highest share of fatalities was recorded in the regions of WarmińskoMazurskie $-38 \%$, Zachodniopomorskie $-34, \%$ and Pomorskie $-34 \%$ of all fatalities.

\section{Roadside hazard identification}

A number of in-the-field tests were conducted looking at road infrastructure and its safety. Based on the findings, a number of elements were identified which present a potential roadside hazard to road users. In 2013 in Poland a road safety inspection method was developed and implemented. The development of the Polish method took account of the experience of other countries [5-7]. Selected sources of hazards were illustrated with photographic documentation (Fig. 3). The sources of Poland's most prevalent roadside hazards include:

- trees close to the edge of the road (up to 3 metres away from the edge of the carriageway the risk is the highest, especially in the area of curves in horizontal alignment, junctions and exits),

- other vegetation obstructing visibility,

- elements of infrastructure which are unyielding (concrete or wooden utility poles, masts, etc.),

- supports of civil engineering objects too close to the edge of the road, unsecured (e.g. bridge supports),

- drainage facilities - vertical concrete front walls of culverts,

- steep embankments,

- poor technical condition of shoulders,

- inadequately terminated, too short, wrong working width and damaged safety barriers.

Photo. 3.1 shows a line of trees along the outer edge of a horizontal curve where the risk of running off the road is much higher than on a straight section or the inner edge of the curve. Photo. 3.2 shows very dangerous safety barrier terminations. Photo. 3.3 identifies a risk in the form of the vertical wall of the culvert. Photo. 3.4 shows the different grade of the carriageway and shoulder, clearly a hazard. All the above examples were identified during a check of Poland's national and regional roads.

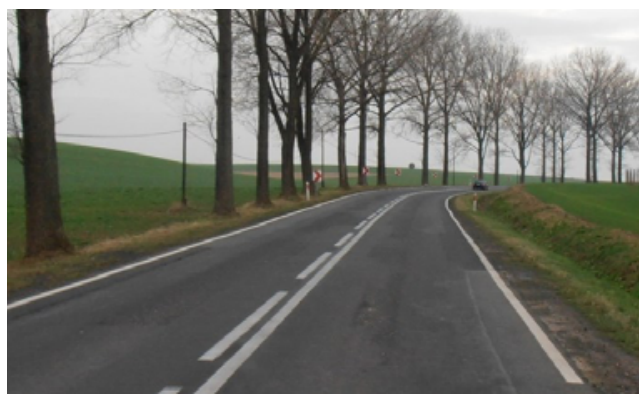

Photo. 3.1

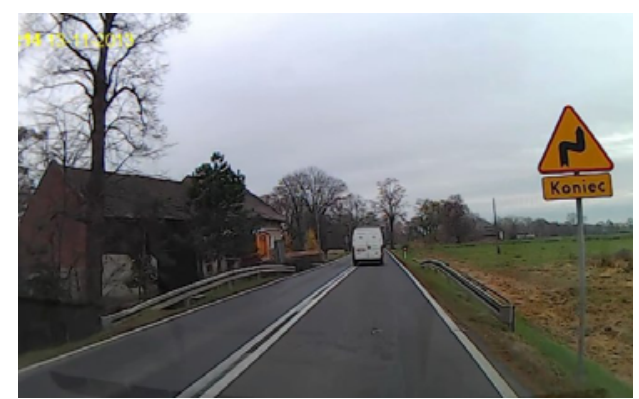

Photo. 3.2 


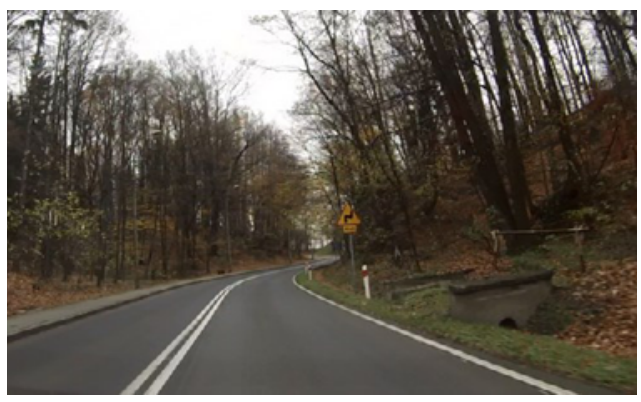

Photo. 3.3

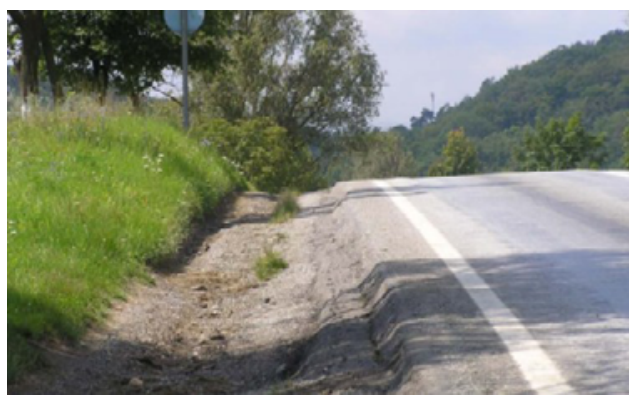

Photo. 3.4

Fig. 3. Examples of roadside hazards.

\section{Methods for solving the problem}

The key to a successful road safety solution lies in an effective road network safety management. A tool proposed in a directive of the European Parliament [8], road safety management fits in with transport safety management in the broad sense. Road network safety management involves a procedure designed to:

- assess safety and identify high-risk sections,

- carry out road safety checks on high-risk sections,

- select the most effective and efficient corrective measures that are appropriate for the funding available,

- communicate the hazards to road users and partners (local authorities, police, partnered businesses),

- monitor safety levels after treatment and evaluate their effectiveness.

Roadside safety management can be delivered at three levels. It begins with the first level which is the strategic level - at the national level. A country's strategic risk in road engineering has to do with its strategic goals such as protecting road users from death or injury, protecting critical infrastructure and strengthening the rescue system. Strategic risk covers the entire system of road transport, including the operation of road infrastructure. Level two is the tactical level and involves regional safety management, i.e. the voivodeship level in Poland. It covers a specific area and identifies the main lines of action. Level three is the operational level and involves concrete objectives at the local level in the area of operating or upgrading a selected road or short road section.

The main factors of hazard at the strategic level that contribute to the severity of run-offroad accidents include: legacy - avenues with roadside trees, speeding because drivers notoriously drive over the speed limit, lack of safe roadside design standards or guidelines, existing infrastructure which "forgives" drivers their mistakes on some sections only.

Subsequent road safety programmes: GAMBIT 2000, GAMBIT 2005, National Roads GAMBIT (sectoral programme for central level road authority) and the National Road Safety Programme 2013 put the emphasis on reducing accident severity as a strategic goal [9-11]. Measures were introduced along with rules for safe roadsides which involved [12]:

- keeping vehicles in lane (signage, narrow hard shoulders),

- use of safety structures (safety barriers, crash terminals),

- upgrading slopes,

- use of safe drainage solutions,

- removing hazardous elements (including trees),

- improving visibility, clarity and consistency of roads. 
Within nine years of GAMBIT 2005 implementation, more than 2,200 people were saved from death as a result of removing potential roadside hazards (mainly trees). Sadly, as many as 6,300 people were killed in that period by striking a tree.

The tactical level covers specific parts of a country, mainly its regions. The main risk factors at the tactical level are: the region (the regions in the north and west have the worst track record on all of their road networks), road category (regional roads constituting the biggest problem), length of road sections with trees, element of the carriageway and time of day (high risk during night-time).

Actions implemented at the strategic level (regional scale only) are: construction of new roads, removal of existing trees, use of safety barriers, speed management, public campaigns and primarily the introduction of roadside safety standards.

The "map of interests" is an example of a regional tactical action (Fig. 4). Developed under an initiative of Regional Police in Olsztyn, the map of the primary road network includes national and regional roads. It features sections that are important because of their:

- functional features: identified by road authorities for their function within the road network and technical class,

- transport needs: proposed by haulier organisations as being important for transport and the regional economy,

- landscape features: outstanding avenues identified by environmental services in a stock taking.

Once the risk of hitting a tree was plotted, the result is a map which identifies clearly the priorities (environment or economy) and hot spots that feature conflict of interest. The final safety management level is the operational level. It covers concrete solutions to be applied locally on selected sections of roads or a smaller administrative area of a county or municipality. The factors which increase risk at this level include all road network deficiencies that exist on a given section (defined in Chapter 3). We can also add: road narrowing (wrong-way driving), restricted visibility at junctions and exits, no space for pedestrian traffic and damaged road infrastructure.

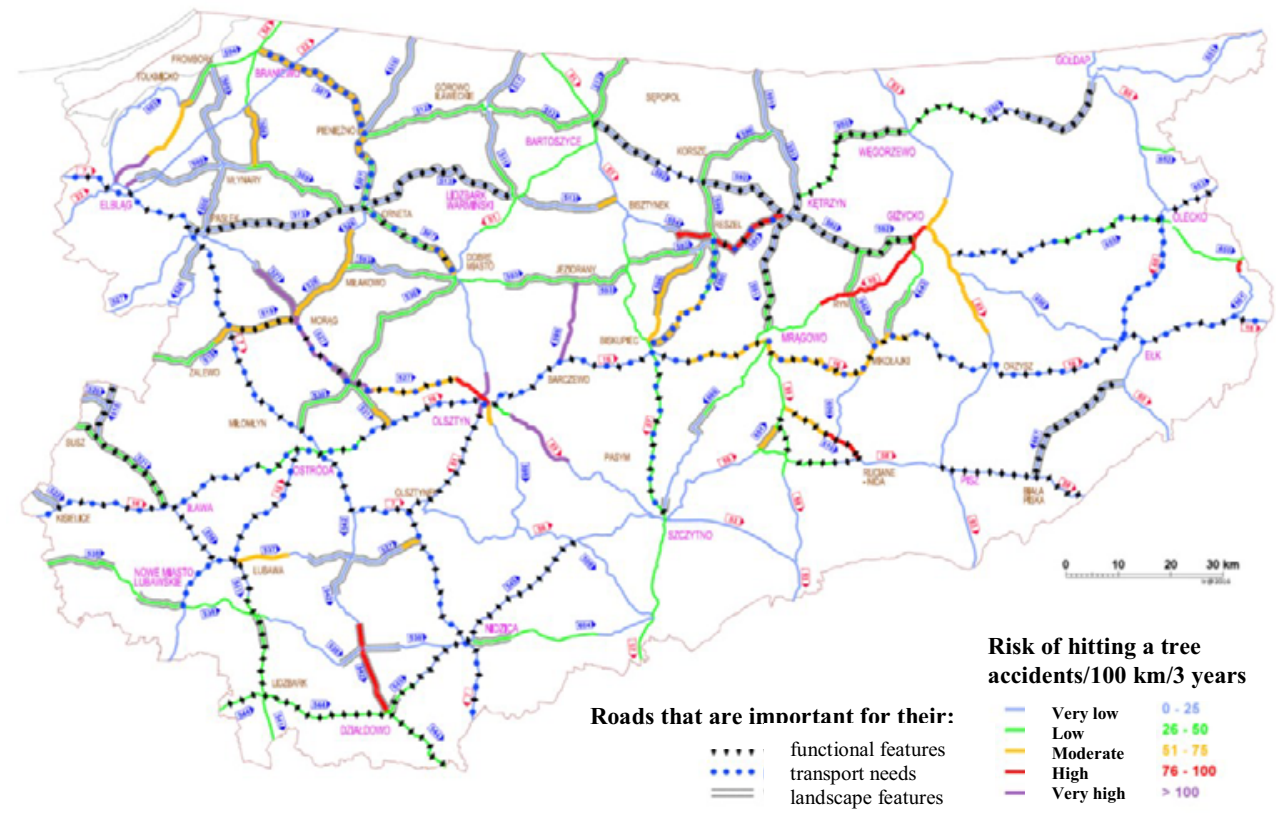

Fig. 4. Map of "interests" in the region of Warmińsko-Mazurskie. 
A major hindrance at this level is that it only has a very small budget to spend on prevention and treatment. The majority of measures involve signage of trees and sections with trees, speed limits and tree removal. As an example, recommended speed is introduced on sections with trees that are close to the road in the region of Warmińsko-Mazurskie (Fig. $5)$.

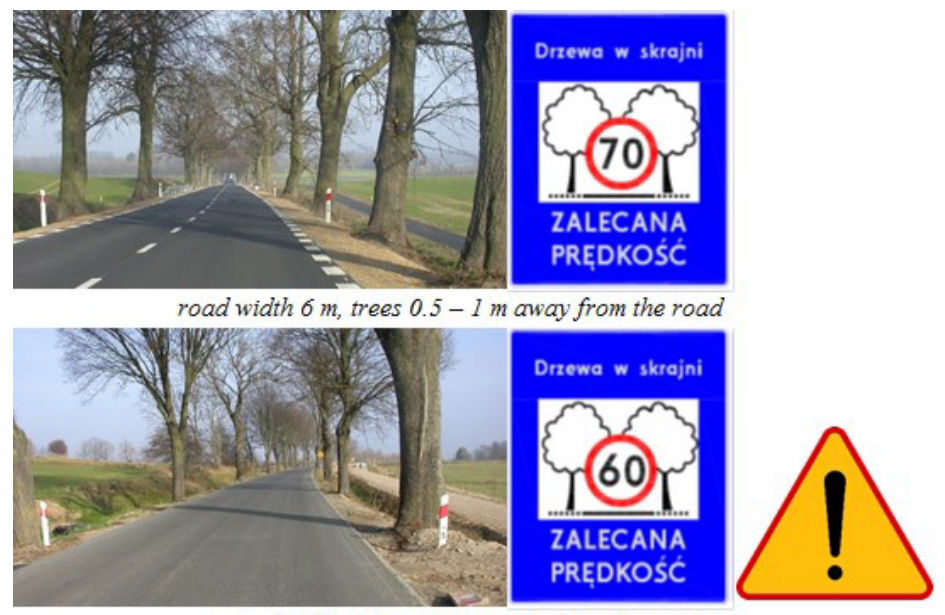

road width $5.5 \mathrm{~m}$, if trees are closer than $0.5 \mathrm{~m}$

Fig. 5. Recommended speed on sections with trees close to the edge.

\section{Conclusions}

Over the last twenty five years more than 20000 people were killed on Polish roads in runoff-road crashes (of which a clear majority involved hitting a tree). Analyses and studies of roadside hazards offer the following conclusions:

1. The main factors that influence the risk of being involved in such a crash are: legacy conditions, road class, length and element of carriageway, hazardous elements at the edge of carriageway (mainly trees), safety measures in place or lack of safety measures.

2. Roadside risk is not the same across Poland. The risk is the highest in the north and west of Poland considering the entire road network; county and regional roads are most at risk among road categories.

3. With no regulations, design standards or cooperation with environmental organisations and institutions, it is very difficult to achieve safety standards and protect road users' lives.

4. To improve roadside safety we must:

- identify the hazards on the road network, conduct checks

- conduct research (build models of the effects of selected factors on road safety. effectiveness evaluation)

- implement safety standards

- develop guidance and principles for safe roadsides

- ensure that there is collaboration between designers, road authorities and environmental organisations and institutions

- exchange experience with other countries.

For years roadside environments have been one of the most neglected aspects of road safety efforts in Poland. Clarity is needed on the effects of roadsides on road safety. We must understand the hazards roadsides cause and implement effective solutions. 


\section{Acknowledgements}

This article was written as part the research project RID 3A - Road safety elements (OT3-3A/PG), funded by the National Centre for Research and Development and the General Directorate for National Roads and Motorways (GDDKiA).

\section{References}

1. M. Budzyński, K. Jamroz, Ł. Jeliński, M. Antoniuk, Why are trees still such a major hazard to drivers in Poland?, Transp. Res. Procedia. 14 (2016)

2. J. Lee, F. Mannering, Analysis of roadside accident frequency and severity and roadside safety management, Research Project T9903 (Washington State Transportation Center (TRAC), Washington, 1999)

3. J.G. Viner, Rollovers on sideslopes and ditches, Accid. Anal. Prev. 27 pp. 483-491 (1995)

4. C. V Zegeer, F.M. Council, Safety relationships associated with cross-sectional roadway elements, Transp. Res. Rec. 1512 pp. 29-36 (1995)

5. S. Cafiso, G. La Cava, A. Montella, G. Pappalardo, Operative procedures for safety inspections on two - lane rural roads, in: IASP, (Catania, Italy, 2006)

6. Road safety inspection guideline for safety checks of existing roads (World Road Association PIARC, France, 2012)

7. Road Safety Inspection RVS 02.02.34 (Bundesministerium für Verkehr, Innovation und Technologie, 2012)

8. Directive 2008/96/EC of the European Parliament and of the Council, On road infrastructure safety management (Brussels, 2008)

9. Gdansk University of Technology, Cracow University of Technology, Motor Transport Institute, GAMBIT 2005 - National Road Safety Programme (Gdansk, Cracow, Warsaw, 2005)

10. Foundation for the Development of Civil Engineering, GAMBIT National Roads Road Safety Programme (Gdansk, 2007)

11. Ministry of Infrastructure and Development, National Road Safety Programme (Poland, 2013)

12. ROSEBUD: Measure against collisions with trees RN134 (landes), WP4 Case Report (Austria, 2005) 